\title{
Concentration Distribution Characteristics of Two-component Fuel Spray under High-pressure Injection Conditions
}

\author{
Dai Matsuda1, Hiroki Saito ${ }^{1}$, Yuki Wakai ${ }^{1}$, Daisuke Kawano², Eriko Matsumura ${ }^{3}$, Jiro Senda ${ }^{3}$ \\ ${ }^{1}$ Department of Mechanical Engineering, Doshisha University, Kyoto, Japan \\ 2Department of Mechanical Engineering, Osaka Sangyo University, Osaka, Japan \\ ${ }^{3}$ Department of Science and Mechanical Engineering, Doshisha University, Kyoto, \\ Japan ${ }^{*}$ Corresponding author email : cyjg1502@mail4.doshisha.ac.jp
}

\begin{abstract}
In present study, a novel fuel design concept for low emission and combustion control in engine systems have been proposed [1][2]. Two-component fuels mixed with different volatility components form a two-phase region where the liquid and vapor of both components co-exist due to the intramolecular interaction. This two-phase region gradually shifts to the lower pressure side due to the early vaporization of the higher volatility component from the droplet. This phenomenon, so-called batch distillation, results in the heterogeneous concentration distribution of the two components in the fuel spray. In this paper, the concentration distribution of two-component fuel was measured by laser induced fluorescence and calculated numerically using a multicomponent fuel model in higher injection pressure than conventional injection conditions. It was found that increasing the injection pressure and ambient density accelerated the mixing, resulting in a similar concentration distribution of each component.
\end{abstract}

Keywords: Multi-component fuel, Batch distribution, Concentration distribution, Mixing

\section{Introduction}

In compression-ignition engines, the physical and chemical properties of the fuel are important factors that control the mixture formation process and the combustion process thereafter. The authors have proposed a fuel design concept of mixing high boiling point fuel with low boiling point fuel as a spray design method for low emission and combustion control in engine systems [1][2]. Figure1 shows the characteristics of the spray formation of a two-component fuel. A multi-component fuel spray model has been proposed to estimate vapor-liquid equilibrium and physical properties of the fuel mixture, and two-component fuel spray has been analyzed using the KIVA code. It is well known that fuel spray is mixed and diluted with small hole diameter nozzle and high-pressure fuel injection. However, no numerical analysis of two-component fuel spray has been performed under the high fuel injection pressures. It is

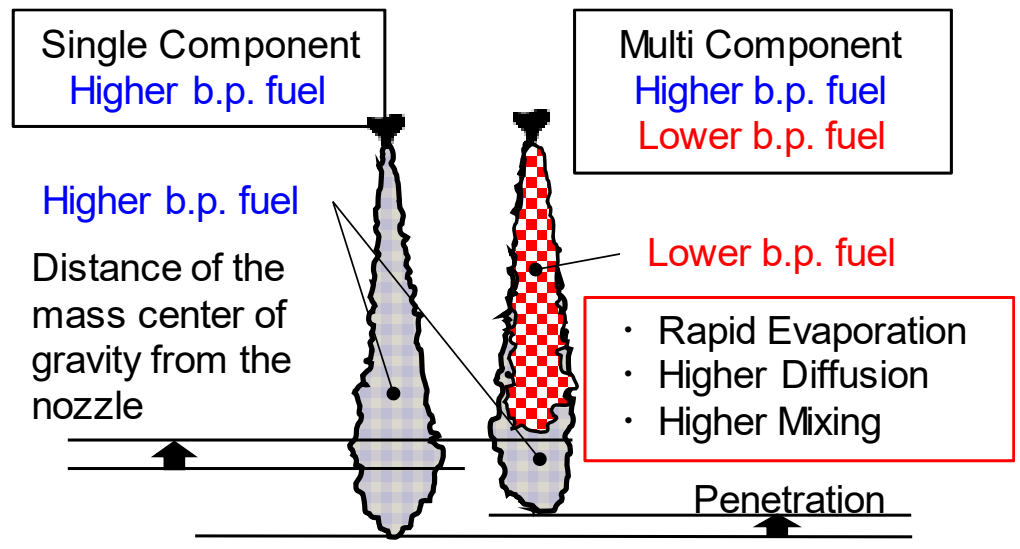

Figure 1. Stratified two-component fuel spray concentration distribution under high pressure injection conditions. 
necessary to select a model to represent the breakup phenomenon of diesel spray under highpressure fuel injection conditions and analyze the heterogeneous concentration distribution unique to two-component fuel spray. In this paper, the spray characteristics were measured using the laser-induced fluorescence method (LIF) for single-component and two-component fuel sprays, and a breakup model suitable for high-pressure injection conditions was selected. The effects of fuel injection pressure and ambient density on heterogeneous component concentrations were also investigated.

\section{Numerical Analysis of Two-Component Fuel Spray}

Various models have been proposed by various research institutes to numerical analyze the spray properties of multicomponent fuels. In order to analyze the physical effects of multicomponent fuels in detail, the multicomponent spray model constructed by Kawano et al [2]. The model gives transport properties of multicomponent fuels shown in Figure 2. The source program of the NIST Mixture Property Database was used to estimate the property values of mixed fuels [3]. The surface tension and diffusion coefficients were calculated separately.

In a high-pressure fuel spray, a liquid column (potential core) is generated in which injection velocity is maintained. On the other hand, in the middle of the spray where the velocity difference with the surrounding gas decreases due to momentum exchange, the breakup due to the deformation of the fuel droplet is considered to be dominant. Therefore, the WAVEMTAB model, which is a combination of the WAVE model, which models the breakup due to the velocity difference with the surrounding gas, and the MTAB model, which models the breakup due to droplet deformation, is considered to be effective [4][5][6][7]. The outline of the model is shown below. The WAVE model simulates the instability due to the speed difference acting on the droplet surface, the breakup phenomenon due to the instability of so-called Kelvin Helmholtz $(\mathrm{KH})$ [4]. The droplet diameter $r_{c}$ after breakup due to the instability of $\mathrm{KH}$ is calculated by equation (1) using the wavelength $\Lambda_{K H}$ which grows at the liquid column or the surface of the droplet at the fastest speed. The division time $\tau_{K H}$ is defined by equation (2).

$r_{c}=B_{0} \Lambda_{K H}$

$\tau_{K H}=\frac{3.726 B_{1} r}{\Omega_{K H} \Lambda_{K H}}$.

Here, $B_{0}$ is the experimental constant, given as $0.61 . B_{1}$ is an experimental constant. The smaller $B_{1}$, the shorter the time required for breakup, hence the breakup is completed early.

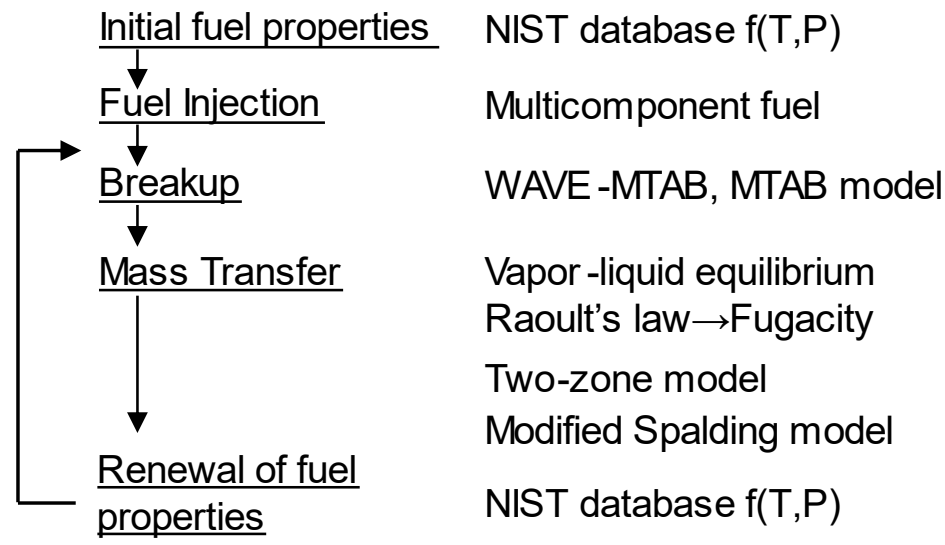

Figure 2. Flowchart of multicomponent fuel model [2] 
Conversely, as $B_{1}$ gets bigger, the time required for breakup becomes longer and the time to complete breakup becomes longer. In this non-evaporative spray analysis, $B_{1}=30$ is given, and numerical calculation is performed.

The droplet breakup process is modelled by Taylor analogy breakup (TAB) model, which is standard stochastic breakup model [5]. In TAB model, oscillations of the droplet are modelled in the framework of a spring mass system and breakup occurs when the oscillations exceed a critical value. The rate of oscillations is given by equation (3). The drop sizes after breakup are determined by an equation based on energy conservation. In this analysis, we assume that the energy of the parent drop before breakup is equal to the combined energies of the product drops after breakup. Thus, Sauter mean diameter $r_{32}$ after breakup is given by equation (4).

$$
\begin{aligned}
& \ddot{y}=\frac{2}{3} \frac{\rho_{g} U_{r}^{2}}{\rho_{l} r^{2}}+\frac{8 \sigma}{\rho_{l} r^{3}} y-\frac{5 \mu_{l}}{\rho_{l} r^{2}} \dot{y} \\
& r_{32}=\frac{r}{1+\frac{8 K}{20}+\frac{6 K-5 \rho_{d} r^{3}}{120} \dot{y}^{2}}
\end{aligned}
$$

Here $K$ is the ratio of the total energy in distortion and oscillation to the energy in the fundamental mode. The value of $K$ must be determined by comparisons with experimentally measured drop sizes. For the distribution of the product drop sizes, $X$-squared distribution with two-degree of freedom is used in TAB model. Senda et al. modified the degrees of freedom to 6 and $K$ to $8 / 9$ under the condition that collision and coalescence were not considered [6].

\section{Experimental and Numerical Analysis Conditions}

The laser sheet light was incident to visualize the spray, and the fluorescence was captured. The images were taken at $0.5 \mathrm{~ms}$ after the start of fuel injection. The concentration distribution images of each component were taken in separate shots. In addition, the fuel remaining in the nozzle tip was removed by creating a negative pressure in the vessel before the experiment. The conditions for the experiments and numerical analyzes are shown in Table 1. The fuel injection nozzle was a single hole nozzle (hole diameter $d_{n}=\varphi 0.125 \mathrm{~mm}$ ), and the fuel injection differential pressure $\Delta P_{\text {inj }}$ was changed from $100 \mathrm{MPa}$ to $60 \mathrm{MPa}$ and $140 \mathrm{MPa}$. The ambient temperature $T_{a}$ was set at $450 \mathrm{~K}$, and the ambient density $\rho_{a}$ was changed from $15.0 \mathrm{~kg} / \mathrm{m}^{3}$ to 16.9 and $18.7 \mathrm{~kg} / \mathrm{m}^{3}$. The experimental conditions were set at an ambient pressure above the saturation pressure of the fuel, where the single-component fuel spray and the multicomponent fuel spray was not under flash boiling conditions. The injection period $t_{i n j}$ was set so that the fuel injection amount $m_{f}$ was $3.2 \mathrm{mg}$, and the fuel injection rate measured by the Bosch injection rate measurement method was input to the numerical analysis as the initial condition. Since the fuel injection pressure was changed, the amount of fuel in the images measured $0.5 \mathrm{~ms}$ after the start of fuel injection was different from each condition. The test fuel was a two-component fuel consisting of a mixture of normal pentane (nC5H12: Pentane) which is a low boiling point component and normal tridecane $(\mathrm{nC} 13 \mathrm{H} 28$ : Tridecane) which is a high boiling point component at a volume fraction of 8:2. It is necessary to select a fluorescence tracer with evaporation characteristics similar to those of the fuel. When measuring the normal tridecane component, 7 vol \% tetralin was added as a fluorescence tracer. When measuring the normal pentane component, 5 vol\% acetone was added as a fluorescence tracer. The saturation vapor pressure curves of the test fuels and fluorescence tracers are shown in Figure 4. The conditions for the numerical models are shown in Table 2. The RNG k- $\varepsilon$ model was used as the RANS turbulence model, and the modified Spalding model was used as the mass diffusion model to simulate the mass diffusion phenomenon 
under high atmospheric pressure conditions. One of the input values, the spray angle, was calculated from the experimental equation by Inagaki and Mizuta [8], and the parcel was formed uniformly within the spray angle. The computational area was $40 \mathrm{~mm}$ in diameter and $100 \mathrm{~mm}$ in height, assumed to be a cylindrical container, and divided into 20, 12, and 80 meshes in the radial, circumferential, and axial directions. The obtained experimental spray image is the cross-sectional information where the test volume is the thickness of the laser sheet light (about $0.4 \mathrm{~mm}$ ), and the calculated results are the central cross-section. Since the fluorescence intensity in the laser-induced fluorescence method is approximately proportional to the fuel concentration, the analysis results can be compared by adding the liquid phase information given in the parcel to the vapor phase information of the fuel given in the mesh [9]. In order to take into account the spatial dispersion of the parcels, which contain thousands of fuel droplets, the number density of the parcels relative to the spray volume was used to

Table 1. Calculation and experimental conditions.

\begin{tabular}{c|c}
\hline \hline Test nozzle & Single Hole $(\varphi 0.125 \mathrm{~mm})$ \\
\hline & nPentane:nTridecane \\
$80: 20$ \\
Test Fuel [vol\%] & 75(Acetone:5):20 \\
(Flourescent tracer) & 80:13(Tetralin:7) \\
& nTridecane \\
& 100 \\
& $93($ Tetralin:7) \\
\hline Differential Pressure of injection $\Delta P[\mathrm{MPa}]$ & $60,100, \quad 140$ \\
\hline Injection Duration $t_{i n j}[\mathrm{~ms}]$ & $1.20,1.07,0.87$ \\
\hline Injection Fuel Amount $m_{f}[\mathrm{mg}]$ & 3.2 \\
\hline Fuel Temperature $T_{f}[\mathrm{~K}]$ & 450 \\
\hline Ambient Gas & $\mathrm{N}_{2}$ \\
\hline Ambient Temperature $T_{a}[\mathrm{~K}]$ & 450 \\
\hline Ambient Density $\rho_{a}\left[\mathrm{~kg} / \mathrm{m}^{3}\right]$ & $15.0,16.9, \quad 18.7$ \\
\hline Ambient Pressure $P_{a}[\mathrm{MPa}]$ & $2.00,2.25,2.50$ \\
\hline
\end{tabular}
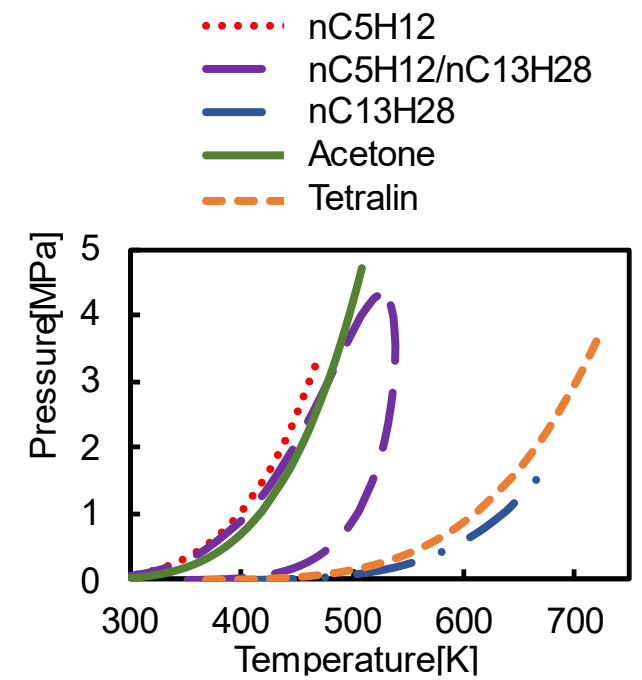

Figure.4 Saturated vapor pressure curve of each fuel and fluorescent tracer in Pressure-Temperature diagram.
Table 2. Calculation methods.

\begin{tabular}{c|c}
\hline CFD code & KIVA3v release2 \\
\hline Turbulent Model & RNG $k$ - $\varepsilon$ model \\
\hline Physical property & NIST Database \\
\hline $\begin{array}{c}\text { Multicomponent } \\
\text { Model }\end{array}$ & $\begin{array}{c}\text { Peng-Robinson equation } \\
\text { Raoult's law }\end{array}$ \\
\hline Spray Model & Discrete Droplet Method \\
\hline Injection Model & Blobs model \\
\hline Breakup Model & WAVE -MTAB Model \\
\hline Collision model & off \\
\hline $\begin{array}{c}\text { Mass Transfer } \\
\text { model }\end{array}$ & Modified Spalding Model \\
\hline Spray angle & Inagaki $\cdot$ Mizuta equation \\
\hline
\end{tabular}


calculate the mass of the parcels in the mesh and the surrounding mesh. In the numerical analysis results, the average concentration within the mesh (about $1 \mathrm{~mm}$ apart) is shown, so the concentration near the nozzle where is no dispersion is under-represented.

\section{Select the Breakup Model}

Conventionally, the MTAB model has been used to model the breakup of multi-component fuel sprays under low injection pressure conditions. In this study, a comparison was made between the WAVE-MTAB model and the MTAB model for the breakup model to analyze a two-component fuel spray. The spatial distribution of each fuel concentration obtained by the laser-induced fluorescence method and the spatial distribution of each fuel concentration in the parcel and fuel obtained by each breakup model at $0.5 \mathrm{~ms}$ after the start of fuel injection are shown in Figure 5. The fluorescence intensity in the laser-induced fluorescence method is corrected by assuming Gaussian distribution of the laser beam [10]. It is approximately proportional to the fuel concentration. The difference in the spray shape of each fuel obtained by the laser-induced fluorescence method was due to shot-to-shot variation and the dilution of the normal pentane component at the outer edge of the spray, which reached the lower limit of the fluorescence intensity measurement. Figure 6 shows the experimental results and the numerical analysis results of the concentration distribution. The experimental results are calculated by using the assumption that the spray is concentric circles and integrating the intensity in three dimensions at each spray axial distance. Therefore, the concentration distribution of the normal pentane component, which has a region below the measurement limit at the spray tip, is evaluated to be small. Compared with the experimental results of the axial concentration distribution of each fuel, the MTAB model overestimates the spray dispersion, resulting in a large difference in the axial concentration distribution, but the accuracy is greatly improved by using the WAVE-MTAB model. For this reason, the WAVEMTAB model was used in the following analyzes.

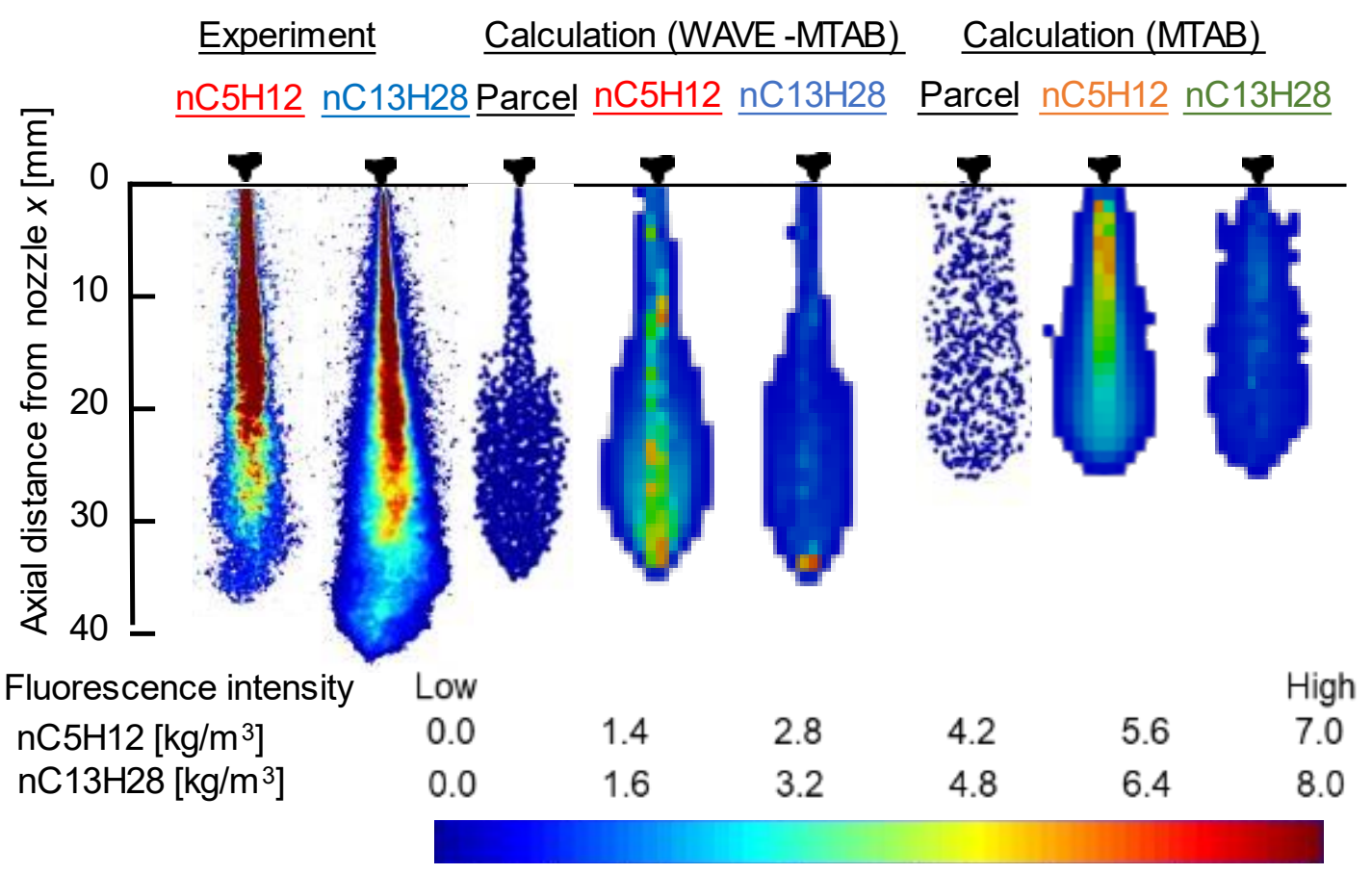

Figure.5 Comparison of concentration distribution of multicomponent fuel spray ASOI $0.5 \mathrm{~ms}(\mathrm{nC} 5 \mathrm{H} 12$ : $\mathrm{nC} 13 \mathrm{H} 28[\mathrm{Vol} \%]=80: 20, \Delta P_{i n j}=100 \mathrm{MPa}, t_{i n j}=1.07 \mathrm{~ms}, m_{f}=3.2 \mathrm{mg}, \rho_{a}=15.0 \mathrm{~kg} / \mathrm{m}^{3}, T_{f}=T_{a}=450 \mathrm{~K}$ ) 


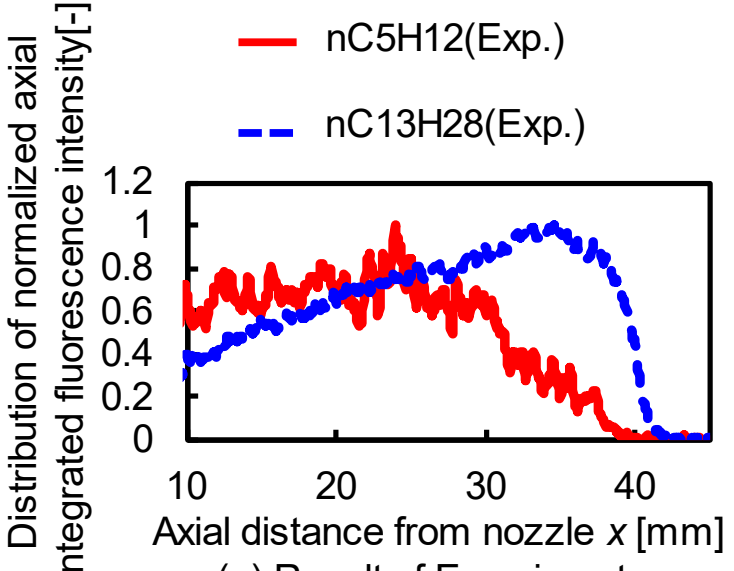

(a) Result of Experiment

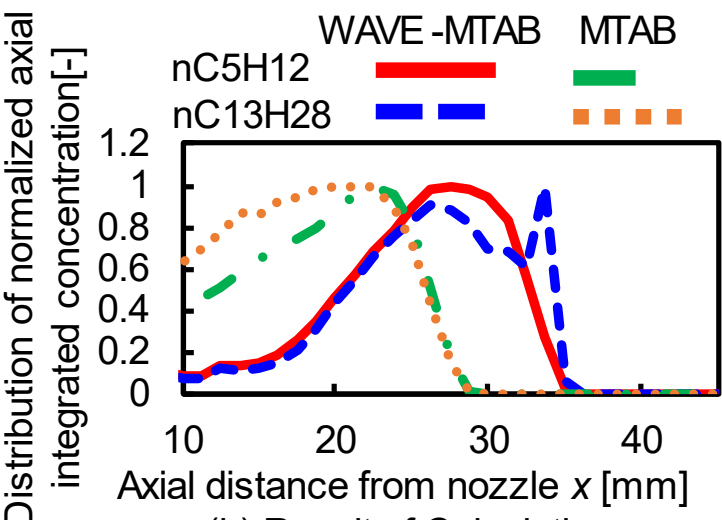

(b) Result of Calculation

Figure.6 Comparison of experimental and calculation results of axial integrated concentration distribution

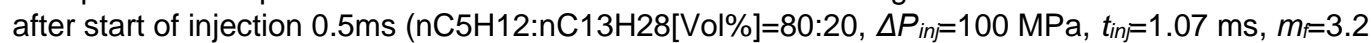
$\left.\mathrm{mg}, \rho_{a}=15.0 \mathrm{~kg} / \mathrm{m}^{3}, T_{f}=T_{a}=450 \mathrm{~K}\right)$

\section{Analysis of Heterogeneity in Concentration}

The spatial distribution of the concentration of each component at $0.5 \mathrm{~ms}$ after the start of fuel injection was obtained by the laser-induced fluorescence method and numerical analysis. Figure 7(a) shows the results with different fuel injection pressures and Figure 7(b) shows the results with different ambient densities. The spray tip penetration and distribution characteristics obtained from these concentration distributions are used to evaluate the heterogeneity characteristics. As a characteristic value of the concentration distribution of each component, the distance of mass center of gravity $X_{\text {mass }}$ of each component in the spray axis direction is defined using the following equation (5).

$$
X_{\text {mass }}=\frac{\int_{0}^{X} x\left(\int_{0}^{R_{r}} C_{f} \cdot \pi r \cdot d r+\int_{0}^{R_{l}} C_{f} \cdot \pi r \cdot d r\right) d x}{\int_{0}^{X}\left(\int_{0}^{R_{r}} C_{f} \cdot \pi r \cdot d r+\int_{0}^{R_{l}} C_{f} \cdot \pi r \cdot d r\right) d x}
$$

Here $C_{f}$ is the fuel concentration, $x$ is the distance from the nozzle to the spray axis, and $r$ is the distance from the spray axis. In the case of two-component fuel sprays, the difference between these values for each component represents the heterogeneity. Comparing the results of the single-component fuel spray with the results of the high-boiling fuel component of the two-component fuel spray shows the change in dispersion characteristics of the highboiling component fuel of the two-component fuel spray due to the mixing of the low-boiling component fuel. The distance of mass center of gravity for different fuel injection pressures at $0.5 \mathrm{~ms}$ after the start of fuel injection are shown in Figure 8. Both experimental and numerical results show that the distance of mass center of gravity is smaller for two-component fuels than for single-component fuels, and that the distance increases with increasing fuel injection pressure. In the experimental results, the exponential value of the distance of mass center of gravity versus fuel injection pressure was 0.15 for the two-component fuel with high boiling point and 0.19 for the fuel with low boiling point. The exponential value of the low boiling point fuel was larger, and the difference in the distance of mass center of gravity of each component became smaller as the fuel injection pressure increased. This indicates that as the fuel injection pressure increases, the injection velocity increases, which promotes turbulent mixing and reduces the heterogeneous concentration of the components due to the difference in evaporation characteristics of the two components. In the numerical results, the exponential values of the distance of mass center of gravity and the distance of mass center of gravity of the high-boiling point fuel versus the fuel injection pressure are close to experimental value. 


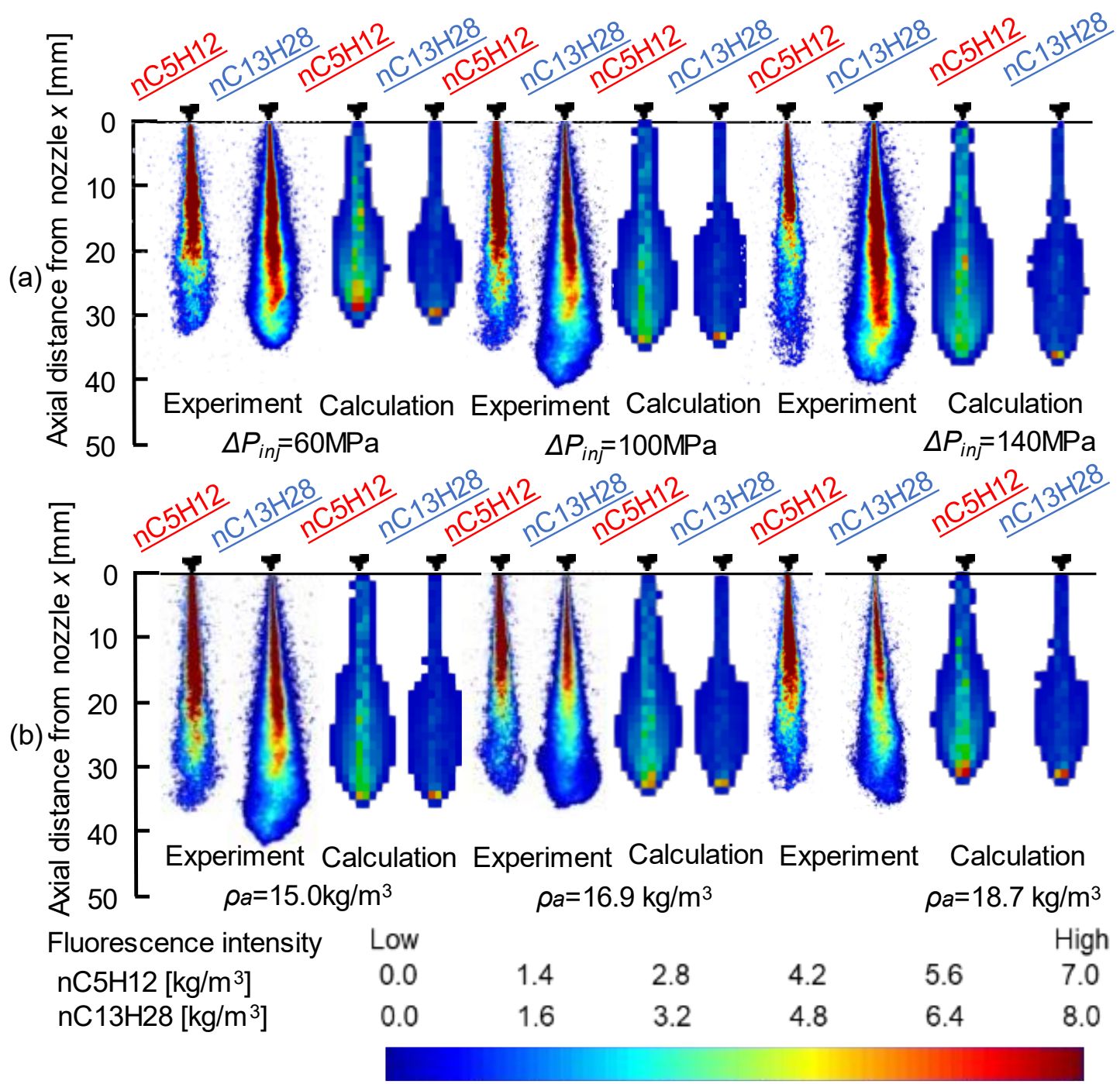

Figure 7. Comparison of concentration distribution of two-component fuel spray after start of injection 0.5 ms a: for Various $\Delta P_{i n j}\left(\rho_{a}=15.0 \mathrm{~kg} / \mathrm{m}^{3}\right)$, b: for Various $\rho_{a}\left(\Delta P_{i n j}=100 \mathrm{MPa}\right)(\mathrm{nC} 5 \mathrm{H} 12: \mathrm{nC} 13 \mathrm{H} 28$ [Vol\%] $\left.=80: 20, m_{f}=3.2 \mathrm{mg}, T_{f}=T_{a}=450 \mathrm{~K}\right)$

The exponential values of the distance of mass center of gravity of the low-boiling point fuel are close in the experiment and calculation, but their values are greatly different. This is probably because the low boiling point fuel component at the outer edge of the spray was dilute in the experiment and the fluorescence intensity reached the measurement limit. Figure 9 shows the distance of mass center of gravity for different ambient densities at $0.5 \mathrm{~ms}$ after the start of fuel injection. The experimental results show that the distance of mass center of gravity of the high-boiling point fuel component of the two-component fuel changed more significantly with the increase of the ambient density than that of the single-component fuel. On the other hand, the low boiling point fuel component did not change significantly, and the difference in the mass center of gravity distance of each component became smaller as the ambient density increased. The numerical results also show that the difference in the distance of mass center of gravity becomes smaller with the increase in the ambient density. It is probably due to the enhancement of mixing inside the evaporated spray.

\section{Conclusions}

In this report, the concentration distribution of two-component fuel was measured by laserinduced fluorescence and calculated numerically using a multicomponent fuel model. It was 
found that the WABE-MTAB model was more suitable than the MTAB model under highpressure injection conditions, and that increasing the injection pressure and ambient density enhanced mixing and resulted in a similar concentration distribution for each component.

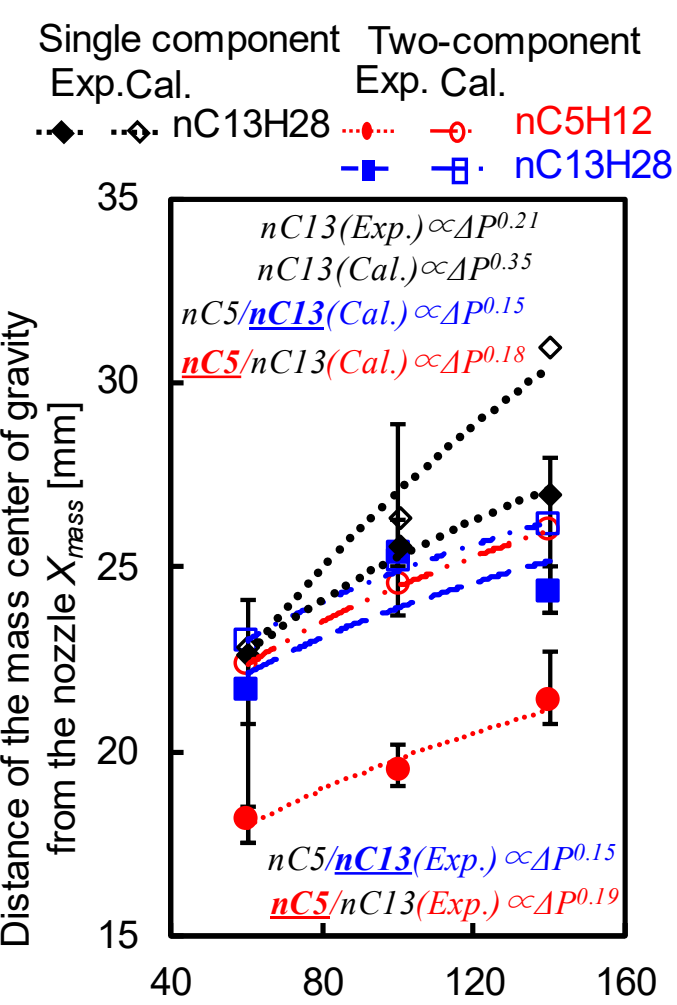

Differential pressure of injection $\Delta P_{i n j}[\mathrm{MPa}]$

Figure.8 Comparison of distance of the mass center of gravity from the nozzle in the spray axial direction for various $\Delta P_{i n j}$ after start of injection $0.5 \mathrm{~ms}(\mathrm{nC} 13 \mathrm{H} 28[\mathrm{Vol} \%]=$ 100, nC5H12: $\mathrm{nC} 13 \mathrm{H} 28[\mathrm{Vol} \%]=80: 20$, $m_{\mathrm{f}}=3.2 \mathrm{mg}, \rho_{a}=15.0 \mathrm{~kg} / \mathrm{m}^{3}, T_{\mathrm{t}}=T_{a}=450 \mathrm{~K}$ )
Single component Two-component Exp.Cal. Exp. Cal.

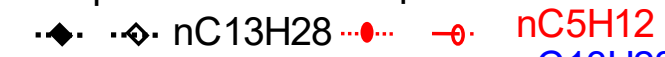

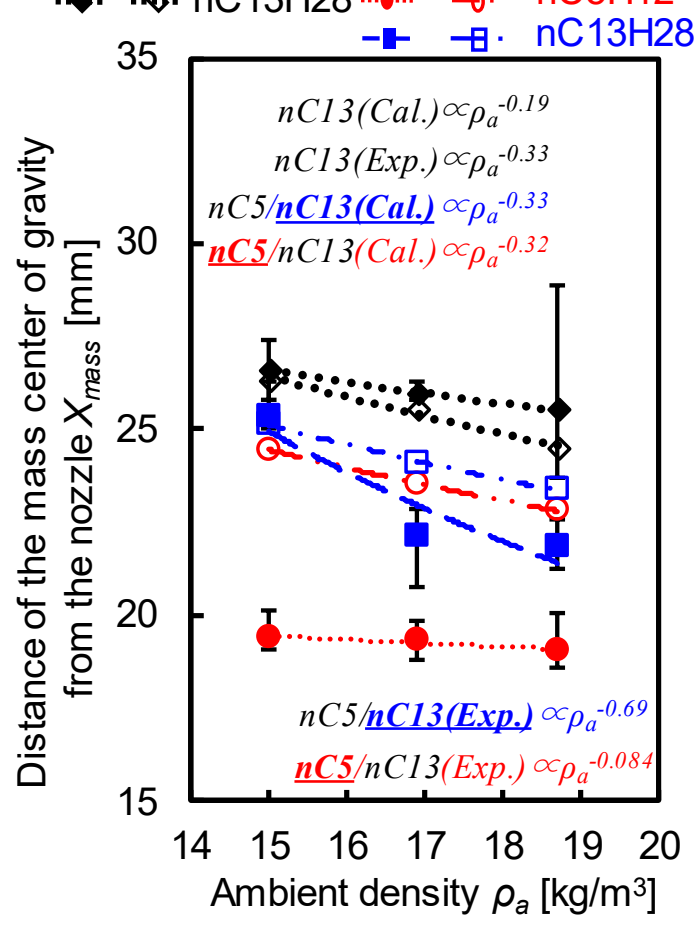

Figure.9 Comparison of distance of the mass center of gravity from the nozzle in the spray axial direction for various $\rho_{a}$ after start of injection $0.5 \mathrm{~ms}$ ( $\mathrm{nC} 13 \mathrm{H} 28[\mathrm{Vol} \%]=$ 100, nC5H12: $\mathrm{nC} 13 \mathrm{H} 28[\mathrm{Vol} \%]=80: 20$, $m_{f}=3.2 \mathrm{mg}, \Delta P_{i n j}=100 \mathrm{MPa}, T_{f}=T_{a}=450 \mathrm{~K}$ )

\section{References}

[1] Senda, J., Kawano, D., Hotta, I., Kawakami, K., Fujimoto, H.,2000, SAE Technical Paper 2000-01-1258.

[2] Kawano, D., Senda, J., Wada, Y., Fujimoto, H., Goto, Y., Odaka, M., Ishii, H., Suzuki, H., 2003, SAE Technical Paper 2003-01-1838.

[3] Friend, J. F.,1992, NIST Mixture Property Database Users' Guide.

[4] Reitz, R. D., 1987, Atomization and Technology, Vol.3, p.309-337.

[5] O'Rourke, P.J., Amsden, A., 1987, SAE Technical paper, No.872089.

[6] Senda, J., Dan, T., Takagishi, S., Kanda, T. and Fujimoto, H., 1997, Proceedings of ICLASS.

[7] Kawaguchi, J., Hanasaki, M., Hori, T., Matsumura, E., Senda, J., 2016, Transactions of Society of Automotive Engineers of Japan, Volume 47, Issue 6, Pages 1311-1316.

[8] Mizuta, J., Inagaki, K., Kawamura, K., Idota, Y., Hashizume, T., 2016, Transactions of Society of Automotive Engineers of Japan, Volume 47, Issue 1, Pages 23-29.

[9] Saito, H., Matsuda, D., Kawano, D., Matsumura, E., Senda, J., 2021, Transactions of Society of Automotive Engineers of Japan, Volume 52, Issue 1, Pages 125-130.

[10] Matsuda, D., Matsumura, E., Senda, J., 2020, Transactions of the JSME (in Japanese), 86 (888), Pages 20-00099 (in Japanese). 